\title{
Nasoseptal flap necrosis: a rare complication of endoscopic endonasal surgery
}

\author{
Joseph D. Chabot, DO, ${ }^{1}$ Chirag R. Patel, MD, ${ }^{2}$ Marion A. Hughes, MD, ${ }^{3}$ Eric W. Wang, MD, ${ }^{4}$ \\ Carl H. Snyderman, MD, MBA, ${ }^{4}$ Paul A. Gardner, MD, ${ }^{1}$ and Juan C. Fernandez-Miranda, MD ${ }^{1}$ \\ Departments of ${ }^{1}$ Neurosurgery, ${ }^{3}$ Radiology, and ${ }^{4}$ Otolaryngology, University of Pittsburgh Medical Center, Pittsburgh, \\ Pennsylvania; and ${ }^{2}$ Department of Otolaryngology, Loyola University School of Medicine, Chicago, Illinois
}

\begin{abstract}
OBJECTIVE The vascularized nasoseptal flap (NSF) has become the workhorse for skull base reconstruction during endoscopic endonasal surgery (EES) of the ventral skull base. Although infrequently reported, as with any vascularized flap the NSF may undergo ischemic necrosis and become a nidus for infection. The University of Pittsburgh Medical Center's experience with NSF was reviewed to determine the incidence of necrotic NSF in patients following EES and describe the clinical presentation, imaging characteristics, and risk factors associated with this complication.

METHODS The electronic medical records of 1285 consecutive patients who underwent EES at the University of Pittsburgh Medical Center between January 2010 and December 2014 were retrospectively reviewed. From this first group, a list of all patients in whom NSF was used for reconstruction was generated and further refined to determine if the patient returned to the operating room and the cause of this reexploration. Patients were included in the final analysis if they underwent endoscopic reexploration for suspected CSF leak or meningitis. Those patients who returned to the operating room for staged surgery or hematoma were excluded. Two neurosurgeons and a neuroradiologist, who were blinded to each other's results, assessed the MRI characteristics of the included patients.

RESULTS In total, 601 patients underwent NSF reconstruction during the study period, and 49 patients met the criteria for inclusion in the final analysis. On endoscopic exploration, 8 patients had a necrotic, nonviable NSF, while 41 patients had a viable NSF with a CSF leak. The group of patients with a necrotic, nonviable NSF was then compared with the group with viable NSF. All 8 patients with a necrotic NSF had clinical and laboratory evidence indicative of meningitis compared with 9 of 41 patients with a viable NSF $(p<0.001)$. Four patients with necrotic flaps developed epidural empyema compared with 2 of 41 patients in the viable NSF group $(p=0.02)$. The lack of NSF enhancement on MR $(p<$ $0.001)$, prior surgery $(p=0.043)$, and the use of a fat graft $(p=0.004)$ were associated with necrotic NSF.
\end{abstract}

CONCLUSIONS The signs of meningitis after EES in the absence of a clear CSF leak with the lack of NSF enhancement on MRI should raise the suspicion of necrotic NSF. These patients should undergo prompt exploration and debridement of nonviable tissue with revision of skull base reconstruction.

https://thejns.org/doi/abs/10.3171/2017.2.JNS161582

KEY WORDS nasoseptal flap; endoscopic endonasal; skull base reconstruction; complication; pituitary surgery

$\mathrm{T}$ HE endoscopic endonasal approach (EEA) has become increasingly more common in the management of ventral skull base lesions. Originally developed for resection of intrasellar lesions, anterior, posterior, and lateral extension of EEA provides access to lesions of the ventral skull base from the frontal sinus to the superior cervical spine, and laterally to the medial middle cranial fossa. . $^{10,19,21,23,24,29,34,43,44}$ Compared with traditional microscopic approaches, EEA may avoid brain manipulation and cosmetic defects, but it was originally associated with an unacceptably high rate of postoperative CSF leakage. . $^{8,9,12,42}$

The routine use of a vascularized nasoseptal flap (NSF) for reconstruction of large skull base defects has drasti-

ABBREVIATIONS BMI = body mass index; EEA = endoscopic endonasal approach; EES = endoscopic endonasal surgery; LOS = length of stay; NSF = nasoseptal flap; $\mathrm{RTOR}=$ return to operating room; $\mathrm{WBC}=$ white blood cell.

SUBMITTED June 23, 2016. ACCEPTED February 2, 2017.

INCLUDE WHEN CITING Published online July 21, 2017; DOI: 10.3171/2017.2.JNS161582. 
cally decreased the incidence of CSF leakage following endoscopic endonasal surgery (EES) by more than half, from $16 \%$ to less than $7 \%$ in a recent systematic review, ${ }^{13}$ with little added comorbidity. $4,28,30,31,39,46$ The decrease in CSF leaks has also led to a decrease in life-threatening meningitis. Critics of EES may point to the prolonged exposure of the intracranial compartment to nasopharyngeal flora during surgery as a potential disadvantage of this surgical corridor. However, as more groups publish their experience with the use of the NSF, the incidence of meningitis remains quite low, from $1.8 \%$ to $5.7 \%$, and is most frequently associated with the presence of a postoperative CSF leak. 2,16,25,27,33

While CSF leakage and meningitis have been well described, there is a paucity of evidence in the literature of the less frequent complications associated with the NSF. This paper describes a series of patients who presented with the clinical signs and symptoms of meningitis and were found to have a necrotic NSF on reexploration. We present the clinical presentation of necrotic NSF, its imaging characteristics, incidence, and risk factors.

\section{Methods \\ Data Collection}

Data collection was approved by the institutional review board of the University of Pittsburgh under a blanket approval for all patients evaluated by the skull base service. Using CPT (Current Procedural Terminology) codes for endoscopic surgery, a list of all patients who underwent EES between January 1, 2010, and December 31, 2014, at the University of Pittsburgh Medical Center was generated. By reviewing the charts of these patients, a second list of all patients for whom a NSF was used for skull base reconstruction was generated. Finally, a third list was generated of all patients who underwent 2 or more EEA procedures during the study period. Patients were included in this final group if they underwent reexploration for suspected CSF leakage or meningitis, but they were excluded if they returned to the operating room for residual tumor or hematoma. The medical records and images of this third group of patients were reviewed.

From the medical records and operative reports, the indications for surgery and the findings of each of these surgeries were determined. Patients were included in the analysis if they underwent endoscopic reexploration (return to OR [RTOR]) for a suspected CSF leak or meningitis. Patients were excluded if the RTOR was for staged surgery, hematoma, recurrent tumor, or if their initial reconstruction did not involve an NSF.

An NSF was determined to be "necrotic" based on a discolored appearance after removal of all overlying debris (Fig. 1) and the lack of active bleeding when incised at the vascular pedicle. Because many flaps can have discoloration along the edges most distal from the blood supply, they were not included in the necrotic NSF group unless $>$ $30 \%$ of the flap showed signs of necrosis.

To determine potential risk factors for the development of NSF necrosis, it was necessary to provide a negative control group for comparison. Because not every patient underwent surgical endoscopic reexploration, a control
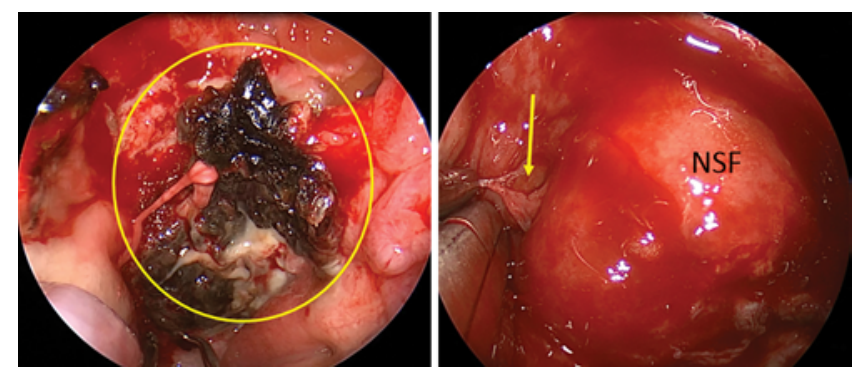

FIG. 1. Intraoperative findings. Left: Intraoperative endoscopic view of a necrotic NSF (circle) after all postoperative debris was removed. Right: Intraoperative endoscopic view of a viable NSF in a patient with a postoperative CSF leak. The arrow denotes the area of dehiscence that led to the development of a CSF fistula. Note the difference in coloration between the flaps and the presence of purulent material over the necrotic flap.

group consisting of patients with CSF leakage and viable flaps was selected to validly correlate the MRI findings with direct endoscopic visualization.

\section{Patient Characteristics}

Age, body mass index (BMI), sex, diabetes, smoking status, and the presence of endocrinopathy were recorded. Prior treatment for the same diagnosis with radiation or surgery was recorded. If the patient had undergone a prior surgery, the choice of surgical approach and where the surgery was performed (our institution vs an outside institution) were recorded. Diagnoses were listed as meningioma, chordoma, and other.

\section{Surgical Variables}

Based on the operative report, the location of the surgical defect was recorded. Descriptions of using EEA to access the ventral skull base extending from the frontal sinus to the upper cervical spine have been previously described in the literature.,10,19,21,22,41,45 Transcribriform and transplanar approaches were listed as "anterior" and the transclival approach was listed as "posterior." Clival defects were further subdivided as superior, middle, and inferior according to published descriptions. ${ }^{19,20}$ Lateral extension of the EEA requiring ligation of the sphenopalatine artery and mobilization of the pterygopalatine space contents, as previously described by our group, ${ }^{21}$ was recorded as "transpterygoid." A patient could belong to multiple groups depending on the choice of approaches (see Table 2).

Standard skull base reconstruction included a dural matrix inlay (DuraGen, Integra LifeSciences), which was followed in some cases by a biological allograft (Surgisis [Cook Medical] or Alloderm [LifeCell]) or fascia lata, and then an NSF. In some recurrent cases, the NSF was reused. Fat grafts, when required, occupied the dead space of the large bony defect underneath the NSF or buttressed the NSF against the skull base. The NSF was held in place by oxidized cellulose (Surgicel, Ethicon), followed by application of fibrin glue and then fibrin-soaked gelatin sponges (Gelfoam, Pfizer). Reconstructions were supported using either nasal Foley catheter balloons or nasal tampons. 


\section{Clinical Presentation}

The indications for RTOR were clinical evidence of CSF leakage or signs and symptoms of meningitis with suspicion of CSF leakage. The signs and symptoms of CSF leakage included headache, nuchal rigidity, or confusion.

All patients with suspected meningitis had preoperative lumbar punctures performed as part of the standard evaluation. The CSF results from the necrotic NSF group were compared with the results from the viable NSF group who presented with symptoms of meningitis ( 9 patients). The evaluated CSF parameters were the white blood cell (WBC) count, neutrophil percentage, protein and glucose levels, and culture positivity. Because several samples were sometimes obtained prior to RTOR, the first sample obtained on readmission was selected for comparison.

\section{Imaging Characteristics}

All patients without a contraindication to MRI underwent imaging using a dedicated skull base MRI protocol with and without intravenous gadolinium-based contrast (MultiHance, Bracco Diagnostics). The protocol used at our institution was previously described by Choby et al. ${ }^{3}$

MRI review was performed by 2 neurosurgeons (J.D.C. and J.C.F.M.) and a neuroradiologist (M.A.H.), who were blinded to each other's results. The MR images obtained in patients in the necrotic NSF group were included if they preceded RTOR by 72 hours or less. In the viable NSF group, the MR image obtained closest to surgery, whether obtained before or after RTOR, was reviewed.

\section{Outcomes}

The method of final skull base repair was recorded, as was the length of stay (LOS). LOS was calculated by adding the number of days in the hospital for the original surgery to the number of days for each admission related to the surgical repair. Determination of final functional status was obtained from the physical examination performed at the last follow-up visit and recorded as "no disability," "some disability," and "death."

The data are presented as the number (\%) for categorical variables and as the mean, standard deviation, and median for continuous variables. Comparisons of the cat- egorical variables between the necrotic NSF group and viable NSF group were performed using the chi-square test and Fisher's exact test. ANOVA and the Wilcoxon rank-sum tests were used to assess the difference between continuous variables when appropriate. All analyses were conducted using SAS (version 9.4), and a $\mathrm{p}$ value $\leq 0.05$ was considered statistically significant.

\section{Results \\ Data Collection}

Of 1285 patients who underwent EES during the study period, a total of 141 patients returned to the operating room (Fig. 2). Sixty-eight patients returned for the second stage of resection or because of a recurrent tumor within the 4-year study period (and were therefore excluded from this evaluation). In addition, 5 patients returned because of postoperative hematoma, 3 patients because of sinonasal infection, and 3 patients underwent a negative reexploration for a presumed CSF leak. Thirteen patients in the RTOR group did not undergo reconstruction with a NSF.

The operative findings of the remaining 49 patients revealed 8 patients with necrotic, nonviable flaps (Supplemental Table 1). The 41 patients with a viable NSF on reexploration were used as the comparison group because they had endoscopic confirmation of a viable flap after all postsurgical debris had been removed.

A review of the operative notes of the 1285 patients who underwent EES revealed 601 patients who had an NSF used in the primary reconstruction. Therefore, the incidence of CSF leakage after NSF use in this series was $7.2 \%$ and the incidence of necrotic NSF was $1.3 \%$. The incidence of necrotic NSF in those patients with a confirmed CSF leak was $18.6 \%$.

\section{Patient Characteristics}

The groups showed no statistical differences in age, sex, BMI, smoking status, or the presence of endocrinopathy or diabetes (Table 1). The diagnoses of the patients with necrotic NSF were meningioma (2 patients), chordoma (3 patients), Rathke's cleft cyst (1 patient), pituitary macroadenoma (1 patient), and aneurysm (1 patient). The

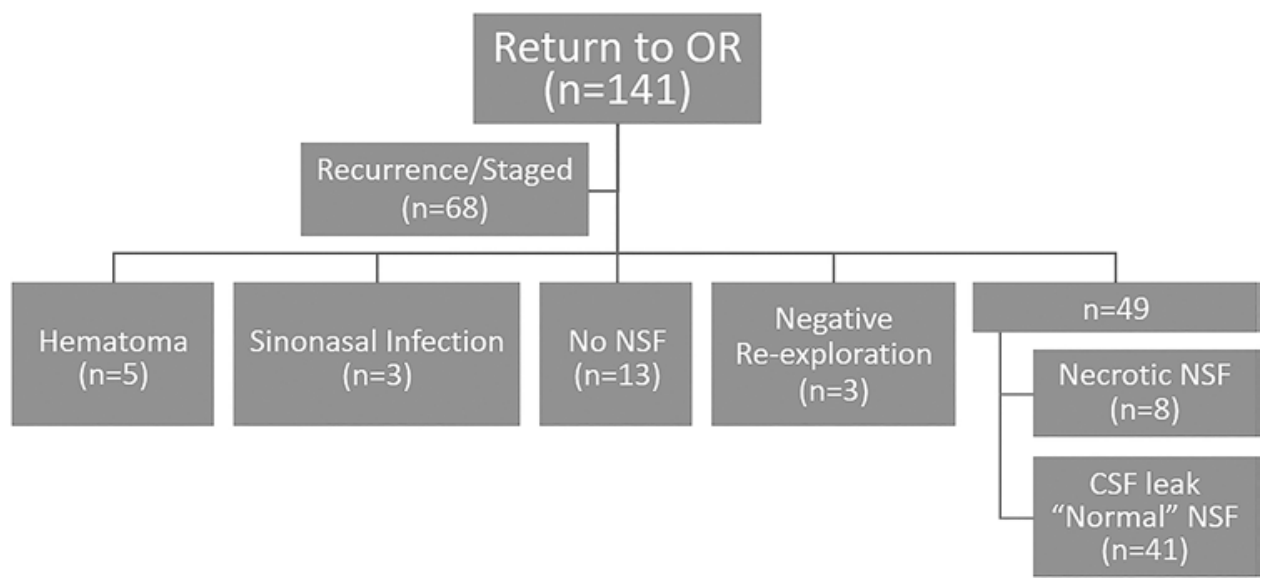

FIG. 2. Search string. A retrospective chart review of all patients who returned to the operating room (OR) during the 4-year study period. 
TABLE 1. Preoperative patient characteristics

\begin{tabular}{|c|c|c|c|}
\hline Characteristic & $\begin{array}{l}\text { Viable } \\
\text { NSF }\end{array}$ & $\begin{array}{c}\text { Necrotic } \\
\text { NSF }\end{array}$ & $\begin{array}{c}p \\
\text { Value }\end{array}$ \\
\hline No. of patients & 41 & 8 & \\
\hline Age, yrs & & & 0.52 \\
\hline Mean & 50.5 & 54.6 & \\
\hline Median & 50 & 58.5 & \\
\hline SD & 15.9 & 17.5 & \\
\hline \multicolumn{4}{|l|}{ Sex } \\
\hline Male & $21(51)$ & $4(50)$ & \\
\hline Female & $20(49)$ & $4(50)$ & 1.0 \\
\hline $\mathrm{BMI}, \mathrm{kg} / \mathrm{m}^{2}$ & & & 0.49 \\
\hline Mean & 33.7 & 28.0 & \\
\hline Median & 34.0 & 25.5 & \\
\hline SD & 7.8 & 5.0 & \\
\hline \multicolumn{4}{|l|}{ Diabetes } \\
\hline Yes & $8(20)$ & $0(0)$ & \\
\hline No & $33(81)$ & $8(100)$ & 0.32 \\
\hline \multicolumn{4}{|l|}{ Smoking } \\
\hline Yes & $7(17)$ & $3(43)$ & \\
\hline No & $34(83)$ & $4(57)$ & 0.15 \\
\hline \multicolumn{4}{|l|}{ Endocrinopathy } \\
\hline Yes & $10(24)$ & $2(25)$ & \\
\hline No & $31(76)$ & $6(75)$ & 1.0 \\
\hline \multicolumn{4}{|l|}{ Diagnosis } \\
\hline Meningioma & $17(42)$ & $2(25)$ & 0.46 \\
\hline Chordoma & $9(22)$ & $3(38)$ & 0.39 \\
\hline Other & $15(37)$ & $3(38)$ & 0.70 \\
\hline \multicolumn{4}{|l|}{ Preop radiation } \\
\hline Yes & $4(10)$ & $2(25)$ & \\
\hline No & $37(90)$ & $6(75)$ & 0.23 \\
\hline \multicolumn{4}{|l|}{ Surgical history } \\
\hline Any prior surgery & $13(32)$ & $6(75)$ & 0.043 \\
\hline Prior intranasal surgery & $7(17)$ & $5(63)$ & 0.015 \\
\hline Intranasal surgery at outside hospital & $1(2.4)$ & $4(50)$ & 0.002 \\
\hline
\end{tabular}

most common diagnosis in the viable NSF group was meningioma (17 patients), followed by chordoma ( 9 patients). Fifteen patients had "other" pathologies, including craniopharyngioma, macroadenoma, esthesioneuroblastoma, sinonasal undifferentiated carcinoma, and epidermoid cyst. There was no statistical significance associated with any particular pathology and the development of a necrotic NSF.

Some patients in both groups had undergone other treatment prior to EES and were included in this study. Two patients $(25 \%)$ in the necrotic NSF group had undergone prior radiation therapy compared with 4 patients $(10 \%)$ in the viable NSF group $(\mathrm{p}=0.21)$. Six $(75 \%)$ of the patients in the necrotic NSF group had undergone prior surgery for the same pathology compared with 13 patients (32\%) in
TABLE 2. Surgical variables

\begin{tabular}{|c|c|c|c|}
\hline Characteristic & Viable NSF & Necrotic NSF & $p$ Value \\
\hline \multicolumn{4}{|l|}{ Approach } \\
\hline Anterior & $20(49)$ & $3(38)$ & 0.72 \\
\hline Transplanar & $20(49)$ & $3(38)$ & 0.71 \\
\hline Transcribriform & $9(23)$ & 0 & 0.32 \\
\hline Posterior & $23(56)$ & $5(63)$ & 1.0 \\
\hline Transclival & $22(54)$ & $5(63)$ & 1.0 \\
\hline Superior & $20(49)$ & $1(13)$ & 0.12 \\
\hline Middle & $21(51)$ & $5(63)$ & 0.71 \\
\hline Inferior & $12(29)$ & $5(63)$ & 0.11 \\
\hline Transpterygoid & $14(34)$ & $3(38)$ & 1.0 \\
\hline Previously used NSF & $6(15)$ & 0 & 0.57 \\
\hline Fat graft* & $8(20)$ & $6(75)$ & 0.004 \\
\hline Buttress & $4(50)$ & $5(83)$ & 0.58 \\
\hline Reconstruction & $5(63)$ & $2(33)$ & 0.63 \\
\hline Allograft reconstruction $†$ & $16(63)$ & $4(50)$ & 0.70 \\
\hline Merocel tampon placement & $33(80)$ & $7(88)$ & 1.0 \\
\hline Nasal Foley catheter placement & $8(20)$ & $1(11)$ & 1.0 \\
\hline Maximum tumor diameter, $\mathrm{cm}$ & & & 0.43 \\
\hline Mean & 3.26 & 2.71 & \\
\hline Median & 3.1 & 2.0 & \\
\hline SD & 1.6 & 0.80 & \\
\hline Maximum size of defect, $\mathrm{cm}$ & & & 0.06 \\
\hline Mean & 3.33 & 2.71 & \\
\hline Median & 3.3 & 2.0 & \\
\hline SD & 1.36 & 0.96 & \\
\hline
\end{tabular}

Values represent the number of patients (\%) unless stated otherwise. Boldface type indicates statistical significance.

* The use of a fat graft is described as a "buttress" if it was used to hold the flap in place; the use of fat is described as "reconstruction" if it was used to eliminate dead space in a large bony defect.

$\dagger$ Reconstruction with biological allograft such as Surgisis or Alloderm in addition to a layered reconstruction with a dural matrix inlay (DuraGen) and NSF.

the viable NSF group, and this relationship reached statistical significance $(\mathrm{p}=0.043)$. This statistical significance increased if the surgery was intranasal $(p=0.039)$ or if the intranasal surgery was performed at another hospital $(\mathrm{p}=0.008)$.

\section{Surgical Variables}

There were no statistically significant associations between the approach and the development of flap necrosis between the 2 study groups (Table 2). Although none of the patients in the necrotic NSF group underwent a transcribriform approach compared with $9(23 \%)$ patients with a viable NSF $(p=0.32)$, anterior fossa approaches were no more likely than posterior fossa approaches to lead to this condition.

Of the 601 patients with an NSF in the study period, 48 patients underwent reconstruction with a previously used NSF. None of the patients with necrotic NSF had a reused NSF, while 6 of the control patients did. Furthermore, none of the patients with prior intranasal surgery at 
an outside hospital had an NSF harvested as part of their original surgery. While flap reuse was significantly associated with CSF leakage $(\mathrm{p}=0.011)$ and meningitis $(\mathrm{p}=$ 0.008 ), it was not associated with flap necrosis.

The use of an allograft onlay as part of a multilayered reconstruction was not associated with the development of necrosis. Using nasal tampons or a Foley catheter to provide structural support showed no association with the development of flap necrosis. However, patients in the necrotic NSF group were more likely to have fat grafts used for reconstruction than those with a viable NSF ( $75 \%$ vs $20 \% ; p=0.004)$. Multivariate analysis was performed to investigate the relationship between the use of a fat graft and surgery at an outside hospital, which showed no statistically significant correlation (Table 2).

Interestingly, the maximum diameter of the tumor and the size of the surgical defect were greater in the viable NSF group than in the necrotic NSF group, although neither association reached statistical significance $(p=0.43$ and $\mathrm{p}=0.06$, respectively).

\section{Clinical Presentation}

Although only 2 patients with necrotic NSF presented with a CSF leak (25\%), all 8 of them displayed the signs or symptoms of meningitis, including fever, headache, neck stiffness, and/or altered mental status (Table 3). In the viable NSF group, which consisted entirely of patients with CSF leaks, only 9 patients presented with symptoms of meningitis $(p<0.001)$. Furthermore, examination of the patients with necrotic NSF frequently revealed a foul smell emanating from their nasal passages, although this finding was inconsistently documented.

All patients with a necrotic NSF presented at least 1 week after their initial surgery (range 7-76 days; mean 24.3 days; median 19.0 days). The patients in the control group with a viable NSF and CSF leakage tended to generally present earlier (range 1-57 days, mean 12.5 days, median 9.0 days; $p=0.05$ ), although the patients with CSF leakage and the signs or symptoms of meningitis also more closely matched those in the necrotic NSF group (range 7-57 days, mean 20.7 days; $\mathrm{p}=0.77$ ).

\section{Infectious Parameters}

At the time of reexploration, 4 (50\%) patients in the necrotic NSF group were found to have an empyema in the space between the NSF and the deeper reconstructive layers, as opposed to 1 patient (2.4\%) in the viable NSF group without necrotic NSFs $(\mathrm{p}=0.004)$. One patient $(12.5 \%)$ in the necrotic NSF group showed bacterial growth on CSF cultures, compared with $3(33 \%)$ of the 9 patients with meningitis symptoms $(p=1.0)$. There was also no significant difference between these groups with respect to the CSF glucose level, CSF protein level, CSF leukocyte count, or neutrophil percentage.

Intraoperative wound cultures from the necrotic NSF group were all positive. Operative cultures obtained from the debrided flaps and empyema grew a variety of gram-negative and gram-positive bacterial pathogens (Supplemental Table 1), the most common of which were Streptococcus and Pseudomonas species, each found in 3
TABLE 3. Clinical presentation and outcomes

\begin{tabular}{|c|c|c|c|}
\hline Characteristic & $\begin{array}{l}\text { Viable } \\
\text { NSF }\end{array}$ & $\begin{array}{c}\text { Necrotic } \\
\text { NSF }\end{array}$ & $\begin{array}{c}p \\
\text { Value }\end{array}$ \\
\hline Time from surgery to diagnosis, days & & & 0.05 \\
\hline Mean & 12.5 & 24.3 & \\
\hline Median & 9.0 & 19.0 & \\
\hline SD & 10.5 & 22.1 & \\
\hline Signs/symptoms of meningitis & $9(22)$ & $8(100)$ & $<0.001$ \\
\hline Epidural empyema & $1(11)$ & $4(50)$ & 0.004 \\
\hline \multicolumn{4}{|l|}{ Infectious parameters* } \\
\hline Positive CSF culture & $3(33)$ & $2(25)$ & 1.0 \\
\hline CSF glucose level, mg/dl & & & 0.40 \\
\hline Mean & 32.3 & 20.4 & \\
\hline Median & 27.0 & 8.5 & \\
\hline SD & 26.8 & 25.6 & \\
\hline CSF protein level, mg/dl & & & 0.63 \\
\hline Mean & 604.1 & 273.5 & \\
\hline Median & 220.0 & 264.5 & \\
\hline SD & 757.9 & 159.8 & \\
\hline WBC count, cells $/ \mathrm{mm}^{3}$ & & & 0.63 \\
\hline Mean & 3312.1 & 2999.5 & \\
\hline Median & 2090.5 & 2711.0 & \\
\hline SD & 3255.8 & 2283.7 & \\
\hline Neutrophil \% & & & 0.63 \\
\hline Mean & 82.9 & 76.6 & \\
\hline Median & 82.0 & 82.0 & \\
\hline SD & 8.0 & 17.3 & \\
\hline Flap enhancement on MRI† & $38(93)$ & $1(13)$ & $<0.001$ \\
\hline LOS, days & & & 0.96 \\
\hline Mean & 13.0 & 18.5 & \\
\hline Median & 10.0 & 16.5 & \\
\hline SD & 12.2 & 13.0 & \\
\hline Follow-up, mos & & & 0.003 \\
\hline Mean & 23.4 & 7.0 & \\
\hline Median & 24.0 & 5.0 & \\
\hline SD & 17.0 & 6.9 & \\
\hline \multicolumn{4}{|l|}{ Disability } \\
\hline Some & $12(29)$ & $3(38)$ & \\
\hline None & $29(71)$ & $5(62)$ & 0.69 \\
\hline
\end{tabular}

Values represent the number of patients (\%) unless stated otherwise. Boldface type indicates statistical significance.

* Infectious parameters were compared between patients with the signs/ symptoms of meningitis and those with normal or necrotic NSFs.

$\dagger$ Eight patients in the necrotic NSF group were evaluated.

patients. One patient had delayed growth of Candida albicans. There was no preponderance of any single pathogen.

\section{MRI Analysis}

MR images were available for review for all patients in the necrotic NSF group and all but 2 of the patients in the viable NSF group. On the contrast-enhanced T1-weighted MR sequences, only 1 (12.5\%) patient in the necrotic NSF group showed uniform enhancement of the NSF com- 


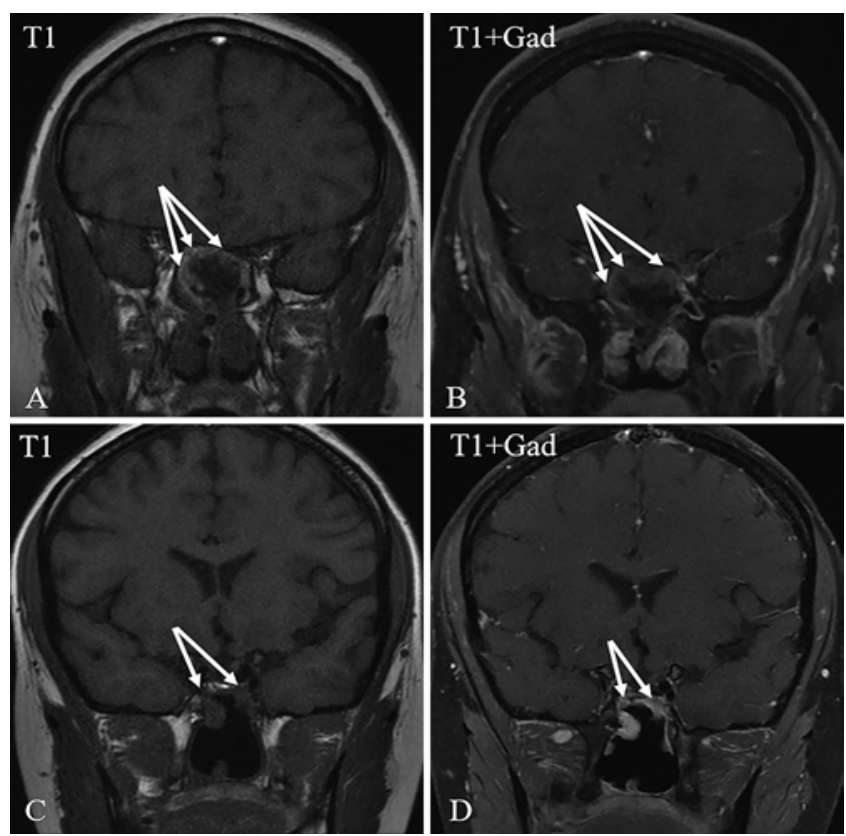

FIG. 3. MRI findings. Postoperative coronal T1-weighted MRI sequences with and without contrast in patients with necrotic ( $\mathbf{A}$ and $\mathbf{B})$ and viable ( $C$ and D) NSFs. The arrows indicate an inverted- $U$ shape conforming to the defect. The necrotic NSF does not enhance with contrast, while the viable NSF shows robust, uniform enhancement.

pared with 38 patients (97\%) in the viable NSF group ( $\mathrm{p}<$ $0.001)$. On blinded analysis of the MR images, there was agreement on all but 2 patients, 1 from each group (kappa score $=0.85 ; \mathrm{p}<0.0001)$. Both of these patients had very thin, patchy enhancement. A single patient in the comparison group, whose NSF did not enhance well on MRI, was found to have a pale NSF on reexploration without evidence of active infection. One patient in the necrotic NSF group whose flap appeared to enhance was found to have only the proximal, inferior part of his NSF viable on reexploration and required debridement because of infection.

Figure 3 demonstrates the differences found on the contrast-enhanced T1-weighted sequences between patients with intact and necrotic NSFs.

\section{Outcomes}

The mean follow-up in the necrotic NSF group was 7.0 months compared with 23.4 months in the comparison group $(\mathrm{p}=0.003)$. Four patients in the necrotic NSF group achieved successful repair with the use of a vascularized inferior turbinate/lateral nasal wall flap, while the other patients were repaired with fat and fascia lata.

In the viable NSF group, the CSF leaks were repaired with flap repositioning, placement of a supplemental fascia lata or allograft, and/or fat graft bolstering. In 3 patients, the NSF flap was of insufficient size for repair, requiring supplemental reconstruction with 1) an inferior turbinate graft, or 2) a vascularized pericranial flap.

The patients in the necrotic NSF group and the patients with meningitis in the viable NSF group were managed with appropriate long-term antibiotic therapy after consultation with the infectious disease department.
The mean LOS was similar between the necrotic NSF and viable NSF groups (18.5 and 13 days, respectively), although patients with meningitis or a necrotic NSF stayed longer than those with a CSF leak and no meningitis symptoms (mean 15.7 and 12.2 days, respectively; $p=0.049$ ).

There was no statistically significant difference in the incidence of disability between groups. There were no deaths in either group during the 30-day postoperative period. There was 1 death in the viable NSF group during the subacute perioperative period at 4 months after reexploration due to bilateral acute subdural hematomas. Two other patients in the viable NSF group died within the 5 -year study period from causes unrelated to their surgeries at $>3$ years after surgery. There were no deaths in the necrotic NSF group during the study period.

\section{Discussion}

Vascularized NSF has been instrumental in decreasing the incidence of CSF leakage following EES. As more clinical centers gain experience with this method of repair, there has been a corresponding increase in the incidence of related complications. Sinonasal discomfort, crusting, septal perforation, loss of olfaction, saddle-nose deformity, mucocele, and CSF fistula have all been described. ${ }^{6,13,15,17}$, 33,35,46,49 The risk of meningitis following CSF leakage has also been well described, as the intracranial compartment is exposed to the pathogens of the aerodigestive tract. ${ }^{16,17,27}$

Although patients with necrotic NSF presented with meningitis based on clinical and laboratory parameters, only 2 patients had CSF leaks. Despite the description of patients with meningitis in the absence of CSF leaks in many large series, none described this clinical phenomenon as a characteristic of a necrotic NSF. ${ }^{17,46,48}$

It is logical that any vascularized flap has the potential to necrose and become a nidus for infection. There are many factors that can place any flap at risk, including patient characteristics, tumor involvement, pedicle compromise (including venous engorgement), and association with nonvascularized tissue. Local wound complications such as this tend to present in a more delayed fashion than CSF leakage or meningitis associated with CSF leakage.

\section{Patient Characteristics}

Risk factors that may contribute to poor wound healing or vasculopathy, such as diabetes, smoking, and age, were not associated with a necrotic NSF. However, patients who underwent prior surgery were significantly more likely to have a necrotic NSF. The role of prior surgery in patients undergoing EEA is important because of the frequency of recurrence of many skull base pathologies and the possibility of increased risk of infection after revision surgery. ${ }^{14}$ This association was stronger with prior intranasal surgery but not with the reuse of a previously harvested NSF. The most likely explanation for this association is compromising the vascular pedicle for the NSF during the previous intervention. In addition, intranasal surgery performed at an outside hospital was another risk factor. One possible explanation is that institutions that anticipate using an NSF are more careful to employ techniques to 
preserve the vascular pedicle from damage during septectomy and sphenoidotomy. . $^{3,38,40}$ Because the details of prior surgeries may not directly reference the status of the vascular pedicle, especially if the surgery was performed prior to the NSF era, endoscopic surgeons should use intraoperative Doppler ultrasound to assess its vascularity ${ }^{37}$ and have a low threshold for resorting to alternative methods of skull base reconstruction..$^{5,32,36,51}$ On the other hand, none of the patients in the necrotic NSF group underwent the takedown and reuse of NSF, as described by Zanation et al. ${ }^{50}$ suggesting that the reuse of the NSF is safe and effective for the integrity of a carefully preserved vascular pedicle.

\section{Surgical Variables}

The location and size of the defect did not contribute significantly to necrotic NSF. Although transpterygoid and transclival approaches should theoretically place the NSF pedicle at greater risk, there was no statistically significant correlation between these approaches and the development of flap necrosis when compared with the anterior approaches. However, because large clival defects are independently associated with an increased risk of CSF leakage, this variable may be overrepresented in the viable NSF group. ${ }^{11}$

Compared with the viable NSF group, using a fat graft was significantly more frequent in patients who developed a necrotic NSF, although the use of other nonvascularized allografts or autografts was not. The use of autologous fat as part of a multilayered repair is a common practice in both endoscopic and open approaches and not typically associated with infection. A review of over 900 open skull base approaches in which a fat graft was used described a very minimal risk of sterile lipoid meningitis, but this was not thought to be infectious in nature. ${ }^{47}$

It is possible that the fat graft is merely a marker and that this association between fat graft use and necrotic NSF may just be because of the the fact that the patients in the necrotic NSF group had less robust flaps as a result of previous surgeries, and therefore supplementation of the reconstruction with fat grafts was used more often. In addition, many larger defects may require transposition of the flap into the ipsilateral maxillary sinus with resultant intraoperative kinking of the pedicle. This can lead to transient ischemia or venous engorgement, both of which could impact long-term flap viability. As a result, it is wise to regularly remove the flap from the sinus intraoperatively to allow reperfusion in such cases. Alternatively, a large fat graft interposed between the fascia and flap may not receive adequate vascularity from the surrounding tissues and become infected. The infected tissue may then cause thrombosis of the flap vessels, resulting in a necrotic NSF secondarily. Despite this finding, our group has not abandoned the use of a fat graft in reconstruction, largely due to its significant impact on the prevention of pontine encephalocele during transclival surgery. ${ }^{26}$

\section{Infectious Findings}

The presence of an epidural empyema was significantly associated with a necrotic NSF, probably because the ne- crotic NSF promoted bacterial overgrowth, especially in the presence of a nonvascularized fat graft. Nonvascularized mucosal tissue (middle turbinate or nasal floor graft) is used frequently for endoscopic repair but is placed in direct contact with vascularized tissues (bone and dura). Similarly, avascular fat and fascial grafts are commonly used, but also are placed in direct contact with vascularized tissues.

\section{MRI Findings}

Kang et al. described the appearance of NSFs on MRI (in 10 patients at different time points following EEA) as a C-shaped layer of tissue conforming to the defect and demonstrating enhancement on MRI. ${ }^{18}$ However, that paper also reported that 2 of the patients had minimal to no enhancement on early MRI, with enhancement returning in 1 of the patients on delayed imaging.

All but 1 of the patients with MRI available to review in the viable NSF group had a completely enhancing NSF. Other studies have confirmed that, while most NSFs enhance avidly and can be used to assess vascularity, ${ }^{1,3,34}$ lack of enhancement does not correlate with a CSF leak or meningitis. Because the patients in other studies did not undergo reexploration, this is the first study to relate the findings on MRI with the appearance of the NSF on endoscopic reexploration.

\section{Outcomes}

Patients with necrotic NSF had similar outcomes to the control cohort with respect to LOS and disability. All patients underwent aggressive surgical debridement, longterm antibiotic therapy, and definitive skull base repair using vascularized pericranial, inferior turbinate, or contralateral NSF, if available. This highlights the importance of prompt diagnosis and management of this clinical scenario. Surgeons may be inclined to attempt antibiotic therapy in patients with symptoms of meningitis and no evidence of a CSF leak; however, this would probably be insufficient to achieve adequate infectious control and may seriously compromise clinical outcome, which should be excellent when the condition is appropriately and promptly treated.

\section{Detection}

Patients with a necrotic NSF essentially have a presentation similar to that of patients with a postoperative wound infection. Therefore, any patient with an unexplained, delayed fever (median 19 days) or convalescence should have their surgical wound evaluated. Given that NSFs are only evaluable with endoscopy and, even then, may be covered by packing or tissue glues, it is wise to keep a high index of suspicion in patients with prior surgery, a large defect, associated fat graft, and nonenhancing flaps. In addition, in our experience, these necrotic flaps (or any local infection) are often associated with a specific foul odor to which the patient may be oblivious, but of which the practitioner should be keenly aware.

\section{Study Limitations}

This study has several limitations other than the biases 
related to its retrospective nature. Using patients with a viable NSF and CSF leakage as a comparison cohort may introduce selection bias with respect to certain characteristics that may be related to both NSF necrosis and the development of a CSF leak. For example, undergoing a transclival approach and having a defect $>2 \mathrm{~cm}-2$ potential independent risk factors for CSF leakage-were both highly represented in the necrotic NSF and viable NSF groups. ${ }^{11,13}$ However, because the importance of the lack of NSF enhancement is unclear, it was necessary for the patients in the comparison group to have undergone endoscopic reexploration so that the viability of the NSF could be adequately assessed.

By limiting the comparison group to patients who underwent endoscopic reexploration, it is possible that some patients who underwent EES during the study period had an NSF that did not enhance on MRI and no related complications. This would suggest that decreased vascularization of an NSF does not always progress to the clinical syndrome described here. Therefore, the lack of enhancement in the absence of associated signs or symptoms of infection does not require clinical intervention, merely close attention.

Although both groups were evenly matched in most demographic criteria, the follow-up period was significantly shorter in the necrotic NSF group than in the viable NSF group ( $p=0.003)$, largely due to the fact that 5 of the 7 necrotic NSF patients were discovered in the last 2 years of the study period. Because there were no major changes in the reconstruction or patient management protocols during the study period, this likely reflects greater institutional awareness of the condition. This might also be explained by the increased number of patients treated with an endonasal approach at an outside institution where the NSF was not adequately preserved or harvested and subsequently required additional surgery.

\section{Conclusions}

Patients with symptoms of meningitis in the early postoperative period and a nonenhancing NSF on MRI should undergo reexploration and debridement urgently, even without the presence of a clinically evident CSF leak. Prior endonasal surgery with potential compromise of the vascular pedicle of the NSF is a risk factor. Prompt recognition and treatment results in good outcomes following this complication.

\section{References}

1. Adappa ND, Learned KO, Palmer JN, Newman JG, Lee JY: Radiographic enhancement of the nasoseptal flap does not predict postoperative cerebrospinal fluid leaks in endoscopic skull base reconstruction. Laryngoscope 122:1226-1234, 2012

2. Brown SM, Anand VK, Tabaee A, Schwartz TH: Role of perioperative antibiotics in endoscopic skull base surgery. Laryngoscope 117:1528-1532, 2007

3. Choby GW, Mattos JL, Hughes MA, Fernandez-Miranda JC, Gardner PA, Snyderman CH, et al: Delayed nasoseptal flaps for endoscopic skull base reconstruction: proof of concept and evaluation of outcomes. Otolaryngol Head Neck Surg 152:255-259, 2015
4. Clavenna MJ, Turner JH, Chandra RK: Pedicled flaps in endoscopic skull base reconstruction: review of current techniques. Curr Opin Otolaryngol Head Neck Surg 23:71-77, 2015

5. Daraei P, Oyesiku NM, Patel ZM: The nasal floor pedicled flap: a novel technique for use in skull base reconstruction. Int Forum Allergy Rhinol 4:937-943, 2014

6. de Almeida JR, Snyderman CH, Gardner PA, Carrau RL, Vescan AD: Nasal morbidity following endoscopic skull base surgery: a prospective cohort study. Head Neck 33:547-551, 2011

7. Fraser JF, Nyquist GG, Moore N, Anand VK, Schwartz TH: Endoscopic endonasal minimal access approach to the clivus: case series and technical nuances. Neurosurgery 67 (3 Suppl Operative):ons150-ons158, 2010

8. Gardner PA, Kassam AB, Snyderman CH, Carrau RL, Mintz AH, Grahovac S, et al: Outcomes following endoscopic, expanded endonasal resection of suprasellar craniopharyngiomas: a case series. J Neurosurg 109:6-16, 2008

9. Gardner PA, Kassam AB, Thomas A, Snyderman CH, Carrau RL, Mintz AH, et al: Endoscopic endonasal resection of anterior cranial base meningiomas. Neurosurgery 63:36-54, 2008

10. Greenfield JP, Anand VK, Kacker A, Seibert MJ, Singh A, Brown SM, et al: Endoscopic endonasal transethmoidal transcribriform transfovea ethmoidalis approach to the anterior cranial fossa and skull base. Neurosurgery 66:883892,2010

11. Gruss CL, Al Komser M, Aghi MK, Pletcher SD, Goldberg AN, McDermott M, et al: Risk factors for cerebrospinal leak after endoscopic skull base reconstruction with nasoseptal flap. Otolaryngol Head Neck Surg 151:516-521, 2014

12. Hadad G, Bassagasteguy L, Carrau RL, Mataza JC, Kassam A, Snyderman CH, et al: A novel reconstructive technique after endoscopic expanded endonasal approaches: vascular pedicle nasoseptal flap. Laryngoscope 116:1882-1886, 2006

13. Harvey RJ, Parmar P, Sacks R, Zanation AM: Endoscopic skull base reconstruction of large dural defects: a systematic review of published evidence. Laryngoscope 122:452-459, 2012

14. Harvey RJ, Smith JE, Wise SK, Patel SJ, Frankel BM, Schlosser RJ: Intracranial complications before and after endoscopic skull base reconstruction. Am J Rhinol 22:516521,2008

15. Horiguchi K, Murai H, Hasegawa Y, Hanazawa T, Yamakami I, Saeki N: Endoscopic endonasal skull base reconstruction using a nasal septal flap: surgical results and comparison with previous reconstructions. Neurosurg Rev 33:235-241, 2010

16. Horowitz G, Fliss DM, Margalit N, Wasserzug O, Gil Z: Association between cerebrospinal fluid leak and meningitis after skull base surgery. Otolaryngol Head Neck Surg 145:689-693, 2011

17. Ivan ME, Iorgulescu JB, El-Sayed I, McDermott MW, Parsa AT, Pletcher SD, et al: Risk factors for postoperative cerebrospinal fluid leak and meningitis after expanded endoscopic endonasal surgery. J Clin Neurosci 22:48-54, 2015

18. Kang MD, Escott E, Thomas AJ, Carrau RL, Snyderman $\mathrm{CH}$, Kassam AB, et al: The MR imaging appearance of the vascular pedicle nasoseptal flap. AJNR Am J Neuroradiol 30:781-786, 2009

19. Kassam A, Snyderman CH, Mintz A, Gardner P, Carrau RL: Expanded endonasal approach: the rostrocaudal axis. Part I. Crista galli to the sella turcica. Neurosurg Focus 19(1):E3, 2005

20. Kassam A, Snyderman CH, Mintz A, Gardner P, Carrau RL: Expanded endonasal approach: the rostrocaudal axis. Part II. 
Posterior clinoids to the foramen magnum. Neurosurg Focus 19(1):E4, 2005

21. Kassam AB, Gardner P, Snyderman C, Mintz A, Carrau R: Expanded endonasal approach: fully endoscopic, completely transnasal approach to the middle third of the clivus, petrous bone, middle cranial fossa, and infratemporal fossa. Neurosurg Focus 19(1):E6, 2005

22. Khan OH, Raithatha R, Castelnuovo P, Anand VK, Schwartz TH: Draf III extension in the endoscopic endonasal transethmoidal, transcribriform approach through the back wall of the frontal sinus: a cadaveric study. World Neurosurg 85:136-142, 2016

23. Komotar RJ, Starke RM, Raper DM, Anand VK, Schwartz $\mathrm{TH}$ : Endoscopic endonasal compared with microscopic transsphenoidal and open transcranial resection of craniopharyngiomas. World Neurosurg 77:329-341, 2012

24. Komotar RJ, Starke RM, Raper DM, Anand VK, Schwartz TH: Endoscopic skull base surgery: a comprehensive comparison with open transcranial approaches. Br J Neurosurg 26:637-648, 2012

25. Kono Y, Prevedello DM, Snyderman CH, Gardner PA, Kassam AB, Carrau RL, et al: One thousand endoscopic skull base surgical procedures demystifying the infection potential: incidence and description of postoperative meningitis and brain abscesses. Infect Control Hosp Epidemiol 32:77-83, 2011

26. Koutourousiou M, Filho FV, Costacou T, Fernandez-Miranda JC, Wang EW, Snyderman CH, et al: Pontine encephalocele and abnormalities of the posterior fossa following transclival endoscopic endonasal surgery. J Neurosurg 121:359-366, 2014

27. Lai LT, Trooboff S, Morgan MK, Harvey RJ: The risk of meningitis following expanded endoscopic endonasal skull base surgery: a systematic review. J Neurol Surg B Skull Base 75:18-26, 2014

28. Langdon C, Enseñat J, Rioja E, Jaume F, Berenguer J, Oleaga $\mathrm{L}$, et al: Long-term radiological findings after endonasal endoscopic approach to the skull base. Am J Otolaryngol 37:103-107, 2016

29. Laufer I, Anand VK, Schwartz TH: Endoscopic, endonasal extended transsphenoidal, transplanum transtuberculum approach for resection of suprasellar lesions. J Neurosurg 106:400-406, 2007

30. Liu JK, Schmidt RF, Choudhry OJ, Shukla PA, Eloy JA: Surgical nuances for nasoseptal flap reconstruction of cranial base defects with high-flow cerebrospinal fluid leaks after endoscopic skull base surgery. Neurosurg Focus 32(6):E7, 2012

31. McCoul ED, Anand VK, Singh A, Nyquist GG, Schaberg MR, Schwartz TH: Long-term effectiveness of a reconstructive protocol using the nasoseptal flap after endoscopic skull base surgery. World Neurosurg 81:136143,2014

32. Meier JC, Bleier BS: Anteriorly based pedicled flaps for skull base reconstruction. Adv Otorhinolaryngol 74:64-70, 2013

33. Naunheim MR, Sedaghat AR, Lin DT, Bleier BS, Holbrook EH, Curry WT, et al: Immediate and delayed complications following endoscopic skull base surgery. J Neurol Surg B Skull Base 76:390-396, 2015

34. Nunes RH, Abello AL, Zanation AM, Sasaki-Adams D, Huang BY: Imaging in endoscopic cranial skull base and pituitary surgery. Otolaryngol Clin North Am 49:33-62, 2016

35. Pant H, Bhatki AM, Snyderman CH, Vescan AD, Carrau RL, Gardner P, et al: Quality of life following endonasal skull base surgery. Skull Base 20:35-40, 2010

36. Patel MR, Taylor RJ, Hackman TG, Germanwala AV, SasakiAdams D, Ewend MG, et al: Beyond the nasoseptal flap: outcomes and pearls with secondary flaps in endoscopic endonasal skull base reconstruction. Laryngoscope 124:846-852, 2014

37. Pinheiro-Neto CD, Carrau RL, Prevedello DM, FernandezMiranda JC, Snyderman CS, Gardner PA, et al: Use of acoustic Doppler sonography to ascertain the feasibility of the pedicled nasoseptal flap after prior bilateral sphenoidotomy. Laryngoscope 120:1798-1801, 2010

38. Rawal RB, Kimple AJ, Dugar DR, Zanation AM: Minimizing morbidity in endoscopic pituitary surgery: outcomes of the novel nasoseptal rescue flap technique. Otolaryngol Head Neck Surg 147:434-437, 2012

39. Rioja E, Bernal-Sprekelsen M, Enriquez K, Enseñat J, Valero $\mathrm{R}$, de Notaris M, et al: Long-term outcomes of endoscopic endonasal approach for skull base surgery: a prospective study. Eur Arch Otorhinolaryngol 273:1809-1817, 2016

40. Rivera-Serrano CM, Snyderman CH, Gardner P, Prevedello D, Wheless S, Kassam AB, et al: Nasoseptal "rescue" flap: a novel modification of the nasoseptal flap technique for pituitary surgery. Laryngoscope 121:990-993, 2011

41. Schwartz TH, Fraser JF, Brown S, Tabaee A, Kacker A, Anand VK: Endoscopic cranial base surgery: classification of operative approaches. Neurosurgery 62:991-1005, 2008

42. Shiley SG, Limonadi F, Delashaw JB, Barnwell SL, Andersen PE, Hwang PH, et al: Incidence, etiology, and management of cerebrospinal fluid leaks following trans-sphenoidal surgery. Laryngoscope 113:1283-1288, 2003

43. Singh H, Grobelny BT, Harrop J, Rosen M, Lober RM, Evans $\mathrm{J}$ : Endonasal access to the upper cervical spine, part one: radiographic morphometric analysis. J Neurol Surg B Skull Base 74:176-184, 2013

44. Singh H, Lober RM, Virdi GS, Lopez H, Rosen M, Evans $\mathrm{J}$ : Endonasal access to the upper cervical spine: part 2-cadaveric analysis. J Neurol Surg B Skull Base 76:262265,2015

45. Snyderman $\mathrm{CH}$, Kassam AB: Endoscopic techniques for pathology of the anterior cranial fossa and ventral skull base. J Am Coll Surg 202:563, 2006

46. Soudry E, Psaltis AJ, Lee KH, Vaezafshar R, Nayak JV, Hwang PH: Complications associated with the pedicled nasoseptal flap for skull base reconstruction. Laryngoscope 125:80-85, 2015

47. Taha AN, Almefty R, Pravdenkova S, Al-Mefty O: Sequelae of autologous fat graft used for reconstruction in skull base surgery. World Neurosurg 75:692-695, 2011

48. Thorp BD, Sreenath SB, Ebert CS, Zanation AM: Endoscopic skull base reconstruction: a review and clinical case series of 152 vascularized flaps used for surgical skull base defects in the setting of intraoperative cerebrospinal fluid leak. Neurosurg Focus 37(4):E4, 2014

49. Vaezeafshar R, Hwang PH, Harsh G, Turner JH: Mucocele formation under pedicled nasoseptal flap. Am J Otolaryngol 33:634-636, 2012

50. Zanation AM, Carrau RL, Snyderman CH, McKinney KA, Wheless SA, Bhatki AM, et al: Nasoseptal flap takedown and reuse in revision endoscopic skull base reconstruction. Laryngoscope 121:42-46, 2011

51. Zanation AM, Thorp BD, Parmar P, Harvey RJ:

Reconstructive options for endoscopic skull base surgery. Otolaryngol Clin North Am 44:1201-1222, 2011

\section{Disclosures}

Dr. Snyderman is a consultant for SPIWay.

\section{Author Contributions}

Conception and design: all authors. Acquisition of data: Chabot, Patel, Hughes. Analysis and interpretation of data: FernandezMiranda, Chabot, Patel, Hughes. Drafting the article: Chabot. Critically revising the article: Fernandez-Miranda, Chabot, 
Hughes, Wang, Snyderman, Gardner. Reviewed submitted version of manuscript: all authors. Statistical analysis: Chabot. Administrative/technical/material support: Chabot. Study supervision: Fernandez-Miranda, Chabot.

\section{Supplemental Information}

\section{Online-Only Content}

Supplemental material is available with the online version of the article.

Supplemental Table 1. https://thejns.org/doi/suppl/10.3171/ 2017.2.JNS161582.

\section{Previous Presentations}

Portions of these data were presented as an electronic poster at the Annual Meeting of the Congress of Neurological Surgeons in New Orleans, Louisiana, September 26-30, 2015, and as an oral presentation at the North American Skull Base Society's 26th Annual Meeting in Scottsdale, Arizona, February 12-14, 2016.

\section{Correspondence}

Juan C. Fernandez-Miranda, Department of Neurological Surgery, University of Pittsburgh Medical Center, 200 Lothrop St., Pittsburgh, PA 15213. email: fernandezmirandajc@upmc.edu. 